\title{
Cardiac symptom attribution and knowledge of the symptoms of acute myocardial infarction: a systematic review
}

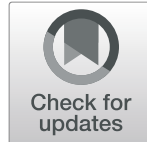

\author{
Benedikt Birnbach, Jens Höpner and Rafael Mikolajczyk *
}

\begin{abstract}
Background: Since the knowledge of the symptoms of acute myocardial infarction (AMI) may reduce the decision time for patients to seek help in case of an AMI, we aimed to summarize evidence on the knowledge of the AMI symptoms and the symptom attribution in case of an acute coronary syndrome (ACS).

Methods: Therefore, we systematically searched the databases PubMed, CINAHL, Embase, and Cochrane Library for relevant studies published between January 1, 2008 and 2019 (last search August 1, 2019).

Results: A total of 86 studies were included, with a composite sample size of 354,497 participants. The weighted mean of the knowledge scores for the symptoms of AMI of 14,420 participants from the general population, was 42.1\% (when maximum score was considered 100\%) and 69.5\% for 7642 cardiac patients. There was a substantially better level of knowledge for six symptoms ('chest pain or discomfort', 'shortness of breath', 'pain or discomfort in arms or shoulders', 'feeling weak, lightheaded, or faint', 'pain or discomfort in the jaw, neck, or back', and 'sweating') (49.8-88.5\%) compared to the four less obvious/atypical symptoms 'stomach or abdominal discomfort', 'nausea or vomiting', 'headache', and 'feeling of anxiety' (8.7-36.7\%). Only $45.1 \%$ of 14,843 patients, who experienced ACS, have correctly attributed their symptoms to a cardiac cause.

Conclusion: In conclusion, we found a moderate to good knowledge of "classic" and insufficient knowledge of less obvious symptoms of AMI. This might suggest that increasing knowledge about less obvious symptoms of AMI could be beneficial. It appears also important to address cardiac attribution of symptoms.
\end{abstract}

Keywords: Acute myocardial infarction, Acute coronary syndrome, Knowledge about symptoms, Symptom attribution, Awareness

\section{Background}

About 15.9 million acute myocardial infarctions (AMIs) occurred in 2015 and the aggregated number of AMIs has increased by $6.4 \%$ from 2005 to 2015 [1]. With an ageing population, and rising prevalence of obesity and diabetes in many countries, the prevention and therapy

\footnotetext{
* Correspondence: rafael.mikolajczyk@uk-halle.de

Institute of Medical Epidemiology, Biometrics and Informatics, Interdisciplinary Center for Health Sciences, Martin-Luther University Halle-Wittenberg, Halle (Saale), Germany
}

of cardiovascular disease will further increase in importance [1].

Since mortality or subsequent morbidity of AMI drastically decreases with a shorter time from symptoms-onset to reperfusion, [2-5] it is important to reduce any delays. One substantial component to ensure a timely treatment is patient delay, the time from symptoms-onset to seeking help. Here, attribution of symptoms to a cardiac cause has been found to be crucial [6-10]. In order to enable the patients to attribute the symptoms to the heart, knowledge of the symptoms of an AMI and the ability to recognize them

(c) The Author(s). 2020 Open Access This article is licensed under a Creative Commons Attribution 4.0 International License, which permits use, sharing, adaptation, distribution and reproduction in any medium or format, as long as you give appropriate credit to the original author(s) and the source, provide a link to the Creative Commons licence, and indicate if changes were made. The images or other third party material in this article are included in the article's Creative Commons licence, unless indicated otherwise in a credit line to the material. If material is not included in the article's Creative Commons licence and your intended use is not permitted by statutory regulation or exceeds the permitted use, you will need to obtain permission directly from the copyright holder. To view a copy of this licence, visit http://creativecommons.org/licenses/by/4.0/ The Creative Commons Public Domain Dedication waiver (http://creativecommons.org/publicdomain/zero/1.0/) applies to the data made available in this article, unless otherwise stated in a credit line to the data. 
seems to be beneficial [11-13]. However, to our knowledge, no review has attempted to summarize the findings on these factors systematically and give an overview of the world-wide knowledge levels of the AMI symptoms.

In our review, we present the current research status on AMI symptoms knowledge by systematically reviewing the literature and comparing the knowledge levels among the general population and cardiac patients. In addition, we report the cardiac symptom attribution among acute coronary syndrome (ACS) patients.

\section{Methods}

\section{Screening process}

$\mathrm{BB}$ and $\mathrm{JH}$ conducted the literature search (Fig. 1) in the databases PubMed, CINAHL, Embase, and Cochrane
Library and searched for publications from January 1, 2008 to 2019 (last search August 1, 2019). For PubMed, we used the search algorithm: "myocardial infarction"[mesh] AND ("chest pain" OR symptom" OR "warning signs") AND ("recognition" OR "awareness" OR interpretation* OR perception* OR incongruence* OR congruence* OR expectation" OR "knowledge" OR "understanding" OR "community intervention" OR "educational intervention" OR campaign*) with the restrictions since 01/01/2008, languages: English or German, only human studies.

The search algorithms can be found in the Expanded methods section in the Additional file 1. We identified 1419 records, of which after deduplication 1014 remained for further analysis. After a further screening process by two reviewers (BB and $\mathrm{JH}), 86$ publications

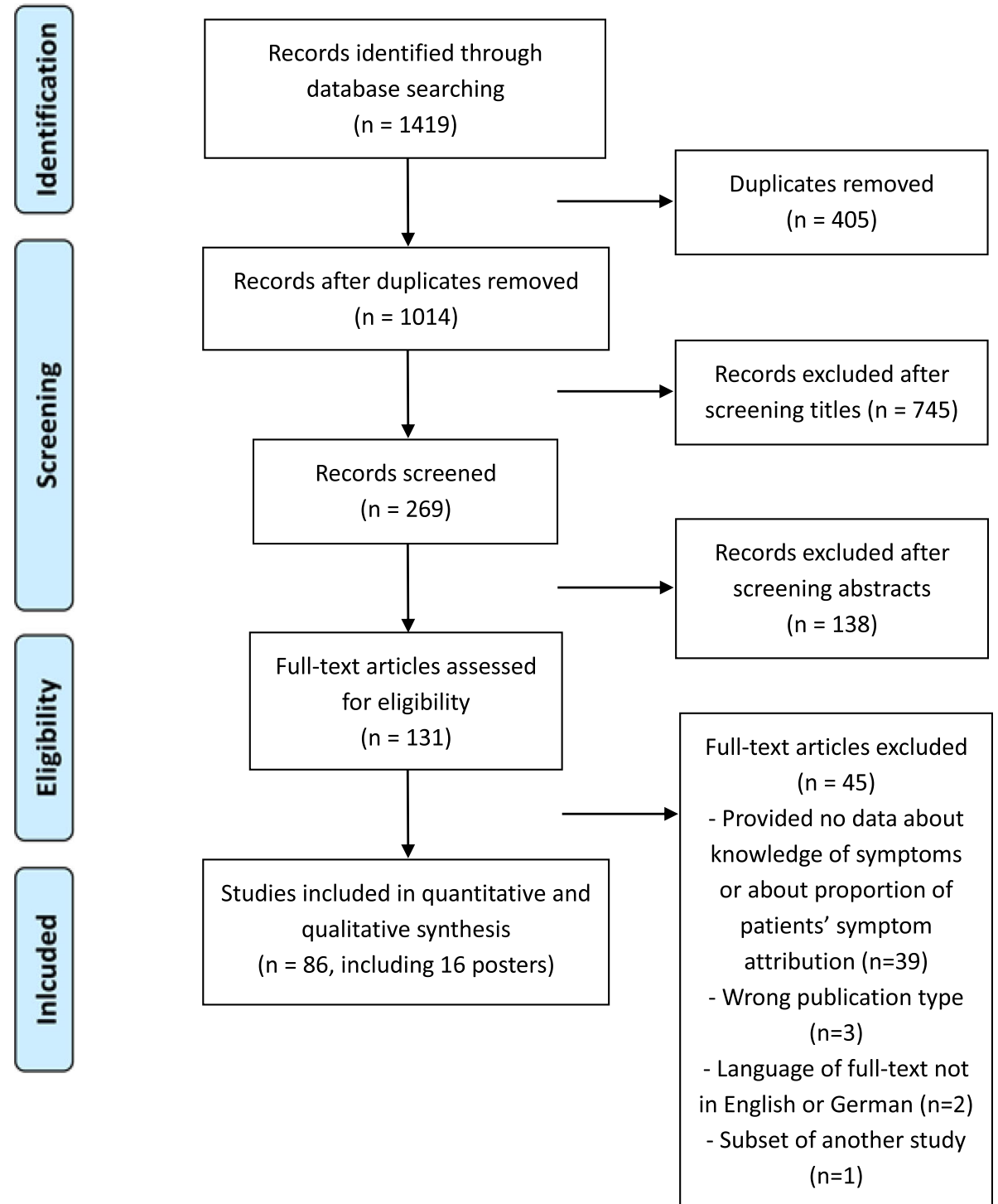

Fig. 1 Screening process - flow chart based on Prisma guidelines [14]. The figure depicts the steps for finding the relevant literature: identification, screening, eligibility, and inclusion of literature 
were included in the analysis, of which 16 were conference abstracts or posters. Among them, 10 publications reported data from interventional studies.

\section{Inclusion criteria}

The inclusion criteria were a sample size of more than 50 participants, date of publication after January 1, 2008, and English or German publication language. We included studies, if they offered data about the knowledge of the symptoms of AMI or data on the attribution of their ACS (AMI or unstable angina) to a cardiac or non-cardiac cause. Review articles, expert opinions or discussions, case reports, and letters were excluded.

\section{Extracted content}

The criteria for the extracted content were set after initial scan of the publications, but before formal extraction started. The primary extraction was conducted by BB, while $\mathrm{JH}$ double-checked the extracted content. In case of discrepancies, $\mathrm{BB}$ and $\mathrm{JH}$ discussed the content and came to a consensus. The table that was used for extraction can be found in Additional file 2.

While there was a variety of methods how knowledge was investigated in these studies, in our review, we examined the knowledge levels (overall knowledge score) given by the studies (sometimes including trap questions and first responder questions), the knowledge level of chest pain as the most common symptom of AMI, [15] and of the 10 most frequently asked symptoms and one trap question. Trap questions were symptoms which usually do not occur in case of an AMI. First responder questions were items that asked about the appropriate response in case of an AMI, for example whether to call the ambulance.

Since previous studies have shown that recognizing symptoms yields higher knowledge scores than recalling them, we looked at open-ended and closed-ended questions separately $[16,17]$. In order to compare the knowledge level in the general population and of cardiac patients, we established the following criteria for these groups:

1) General population: we included participants from studies which had as inclusion criteria an age range with a lower bound of 30 years or younger, and an upper bound of 60 years or older. In that way, we excluded studies which only included young or older participants. Additionally, the studies should not focus on a risk group, a certain ethnicity, or clinical staff, and should not include only one gender.

2) Cardiac group: we included samples of patients of any age that had a history of coronary artery disease
(CAD) or a cardiac event, did not focus on a different risk group, and similarly did not focus on a certain ethnicity, on clinical staff, or only included one gender.

In this analysis, we only included conference abstracts or posters, when it was evident, whether open- or closed-ended questions were used. The data that we extracted from interventional studies was from the baseline data set or if not available, only extracted from the control group post intervention.

Finally, in order to evaluate the cardiac patients' interpretation of their symptoms in case of an ACS, we assessed the symptom attribution in a ST-elevation myocardial infarction (STEMI) group, an ACS group that excluded the patients from the STEMI group, and a group including all cardiac patients.

\section{Quality assessment}

$\mathrm{BB}$ and $\mathrm{JH}$ conducted a quality assessment based on the adapted version of the Newcastle Ottawa scale that has been used in previous studies to assess the quality of cross-sectional studies $[18,19]$. Both authors assessed the studies, discussed the differences in assessment and finally unanimously agreed on a grading. The scale consisted of four questions about Selection (S1-S4), one question about Comparability (C1) and two questions about Outcome (O1, O2). Maximally 10 stars could be allocated. An overview of the allocated number of stars for each study can be found in Additional file 2 and a detailed report of the quality assessment in Additional file 3.

\section{Data analysis and reporting}

For the purpose of comparing and summarizing the knowledge levels, we standardized the reported knowledge scores. The standardized score (the overall knowledge score in further text) is the mean knowledge score in the group, divided by the value that could maximally be achieved, multiplied by $100 \%$. When calculating crude arithmetic mean, the overall knowledge score of each sample had the same weight. When calculating the weighted arithmetic mean, the weight of the overall knowledge score of each sample was based on the number of participants in each sample. For all analyses, we used SAS version 9.4.

\section{Results}

\section{Study selection and quality assessment}

Of the 86 included studies [9-11, 16, 20-101], 10 studies $[44,60,72,73,75-77,80,81,84]$ were interventional studies and could therefore not be rated with the adapted Newcastle-Ottawa-Scale. The remaining 76 studies were allocated a mean of 4.9 stars. Of those studies, 16 studies were conference abstracts which could 
only be assessed partly since some information about the studies was not included in the abstracts [30, 87101]. Hence, only evaluating the available information the mean number of stars for these studies was 3.2. The 60 full-text articles that we assessed were allocated a mean of 5.4 stars. However, this relatively low number of stars can be explained by questions $\mathrm{S} 4$ and $\mathrm{C} 1$ which ask about the exposure and confounders. Since in 11 of those 60 studies the scientific question did not contain any exposure, and consequently no need for identifying confounders, those publications could be allocated no more than 6 stars instead of 10 (mean of the 11 studies: 3.0 out of 6 stars).

For our purpose only two criteria appeared relevant: representativeness of the sampling and response proportion. The representativeness was mostly rated high (mean: 0.9 out of 1 star), the response proportion was often high, too, but in only one study the comparability of responders and non-responders with respect to sociodemographic variables and clinical history was established.

\section{Study characteristics}

The participants of the identified 86 studies were from 34 different countries. Several studies included samples from various countries, and we considered them as separate units (98 samples in total). A figure depicting the composition of countries can be found in the Additional file 1 (Additional figure 1). There were 26 samples from North America (27.1\%), 25 from Europe (26.0\%), 21 from East and South Asia (21.9\%), 10 from Oceania (10.4\%), nine from the Middle East (9.4\%), and the remaining five from North/West Asia, South America, and West Africa (5.2\%). Two conference abstracts did not specify where the samples were located.

Considering United Nations Human Development Index (HDI), [102] 69 samples (71.9\%) were from 24 countries with a very high HDI, 19 samples (19.8\%) from 10 countries with a high HDI, seven samples $(7.3 \%)$ from three countries with a medium HDI, and one sample (1.0\%) from a country with a low HDI.

The composite sample size of all studies was 354,497 , excluding one study because information of sample size was not given [55]. The sample sizes ranged from 51 participants [81] to 76,864 [21] with a median of 400 . Of all the included participants, $51.4 \%$ were male.

In the following analyses, the number of included studies varies as some outcomes were not reported by all studies.

\section{Overall knowledge score Closed-ended questions}

19 studies (27 samples) that used closed-ended questions reported a knowledge score. The studies designed their knowledge scores by offering a list to the participants with symptoms, and sometimes additionally with first responder questions or trap questions. The more symptoms the participants correctly identified and the more questions they answered correctly, the higher the score. Since the lists only had minor differences, we used the provided knowledge score of each study, standardized it to an overall knowledge score (dividing by maximum score value in the given study) and afterwards calculated the weighted mean and crude mean of all overall knowledge scores (see Methods, data analysis and reporting). The differences among the studies were that 11 samples were asked only about AMI symptoms, five additionally received one or more trap questions, one a first responder question, and two samples both, a first responder and a trap question. If the studies included participants that were not within the scope of the requirements for the population group or cardiac group that we defined above, we excluded the studies. Furthermore, we excluded studies that asked the patients what symptoms they had expected rather than asking for knowledge of symptoms. The weighted mean in the population group ( $42.1 \%$ of the maximal score) was substantially lower than in the cardiac group (69.5\%) (Table 1).

\section{Open-ended questions}

In the two studies that used open-ended questions, participants were asked about the symptoms, and the interviewer ticked off the items mentioned on an a priori defined list. The knowledge scores were lower than in most samples that were asked closed-ended questions, with $31.4 \%$ for the population group and $33.3 \%$ in the cardiac group.

\section{Chest pain knowledge \\ Closed-ended questions}

With regard to the assessment of chest pain knowledge, when closed-ended questions were used, patients were given a list of symptoms that included chest pain and were asked: "Which of the following do you think is a symptom of a heart attack?" The phrasing of the question and description of the symptom differed in some studies. We included eight studies (16 samples) for the analysis of the population group and four studies (four samples) for the analysis of the cardiac group. Here, we also excluded studies that did not meet our requirements for population or cardiac group as defined above, or that asked about expectations rather than knowledge. Among both groups the knowledge of chest pain as symptom of AMI was similar (weighted means $88.2 \%$ vs. $86.2 \%$ ) (Table 2).

\section{Open-ended questions}

When open-ended questions were used, the chest pain knowledge depicted the percentage of participants in 
Table 1 Overall knowledge score

\begin{tabular}{llllll}
\hline $\begin{array}{l}\text { Composition of sample, form of } \\
\text { question }\end{array}$ & $\begin{array}{l}\text { Number of } \\
\text { samples }\end{array}$ & $\begin{array}{l}\text { Number of } \\
\text { countries }\end{array}$ & Participants & $\begin{array}{l}\text { Crude mean [\%] } \\
\mathbf{a}\end{array}$ & $\begin{array}{l}\text { Weighted mean [\%] } \\
\mathbf{b}\end{array}$ \\
\hline Population group, closed-ended & 10 & 10 & 14,420 & 36.5 & 42.1 \\
Cardiac group, closed-ended & 5 & 5 & 7642 & 54.7 & 69.5 \\
Population group, open-ended & 1 & 1 & 302 & 31.4 & 31.4 \\
Cardiac group, open-ended & 1 & 1 & 137 & 33.3 & 33.3 \\
\hline
\end{tabular}

The table depicts the results by comparison of composition of sample and form of question used

${ }^{a}$ mean score in each study was standardized by dividing the mean by the maximum score; thus, the numbers report means in terms of percentage of maximum score

bas above; average mean was calculated from means from individual studies weighted by sample size

each sample who reported chest pain, when asked to tell the interviewer about symptoms of a heart attack. For the analysis in the population group, we included four studies (four samples). We found a weighted mean (74.3\%) that was smaller than in the group that was asked closed-ended questions. There was only one study including cardiac patients, which also reported a slightly smaller value (82.0\%).

\section{Comparison of individual symptoms}

When counting the different symptoms that the studies asked about and neglecting different phrasing or minor differences in the description of the symptoms, the studies assessed the knowledge of 26 different symptoms and 14 different trap symptoms.

In the following, we compared the 10 most frequently asked symptoms and the one most frequently asked trap symptom. For the purpose of description, we refer to a symptom as moderately known, if it is known by more than a third of all participants, and otherwise as insufficiently known.

\section{Population group}

In the population group, there were eight studies (16 samples) that applied closed-ended questions. Of those, two were convenience samples (studies 7, 8 in Table 3), and the remaining 14 samples were representative samples.

Closed-ended questions When closed-ended questions were used, the six symptoms 'chest pain or discomfort', 'shortness of breath', 'pain or discomfort in arms or shoulders', 'feeling weak, lightheaded, or faint', 'pain or discomfort in the jaw, neck, or back', and 'sweating' were moderately known (weighted mean: $49.8-88.2 \%$ of respondents who recognized the given symptom as a symptom of AMI) (Table 3). The mean of the weighted means of the moderately known symptoms was $68.7 \%$.

Within the group of moderately known symptoms, only the symptoms 'chest pain or discomfort' and 'sweating' were known in all samples by more than half the participants. However, it should be noted that the symptom 'sweating' was only assessed in three samples. Furthermore, the four symptoms 'stomach or abdominal discomfort', 'nausea or vomiting', 'headache', and 'feeling of anxiety' were insufficiently known (weighted mean: 8.7-28.0\%).

The weighted mean proportion of participants attributing the trap symptom 'sudden trouble seeing in one or both eyes' to AMI was $32.2 \%$ (Table 3), which suggests that there is confusion among some participants to differentiate between the symptoms of stroke and AMI. However, this trap symptom was only assessed in three samples.

Open-ended questions When open-ended questions were asked, for every symptom, the weighted mean of the knowledge scores was lower than in the studies that used closed-ended questions. Since the two studies (two samples) which applied open-ended questions were convenience samples, we refrain from more detailed observations.

Table 2 Knowledge of chest pain as symptom of acute myocardial infarction

\begin{tabular}{llllll}
\hline $\begin{array}{l}\text { Composition of sample, form of } \\
\text { question }\end{array}$ & $\begin{array}{l}\text { Number of } \\
\text { samples }\end{array}$ & $\begin{array}{l}\text { Number of } \\
\text { countries }\end{array}$ & Participants & $\begin{array}{l}\text { Crude mean [\%] } \\
\mathbf{a}\end{array}$ & $\begin{array}{l}\text { Weighted mean [\%] } \\
\mathbf{b}\end{array}$ \\
\hline Population group, closed-ended & 16 & 14 & 145,631 & 83.5 & 88.2 \\
Cardiac group, closed-ended & 4 & 3 & 932 & 79.4 & 86.2 \\
Population group, open-ended & 4 & 4 & 7937 & 76.5 & 74.3 \\
Cardiac group, open-ended & 1 & 1 & 251 & 82.0 & 82.0 \\
\hline
\end{tabular}

The table depicts the results by comparison of composition of sample and form of question used

${ }^{a}$ mean score in each study depicts the percentage of participants recognizing chest pain as symptom of acute myocardial infarction

bas above; average mean was calculated from means from individual studies weighted by sample size 
Table 310 most frequently asked symptoms and one trap symptom in the population group

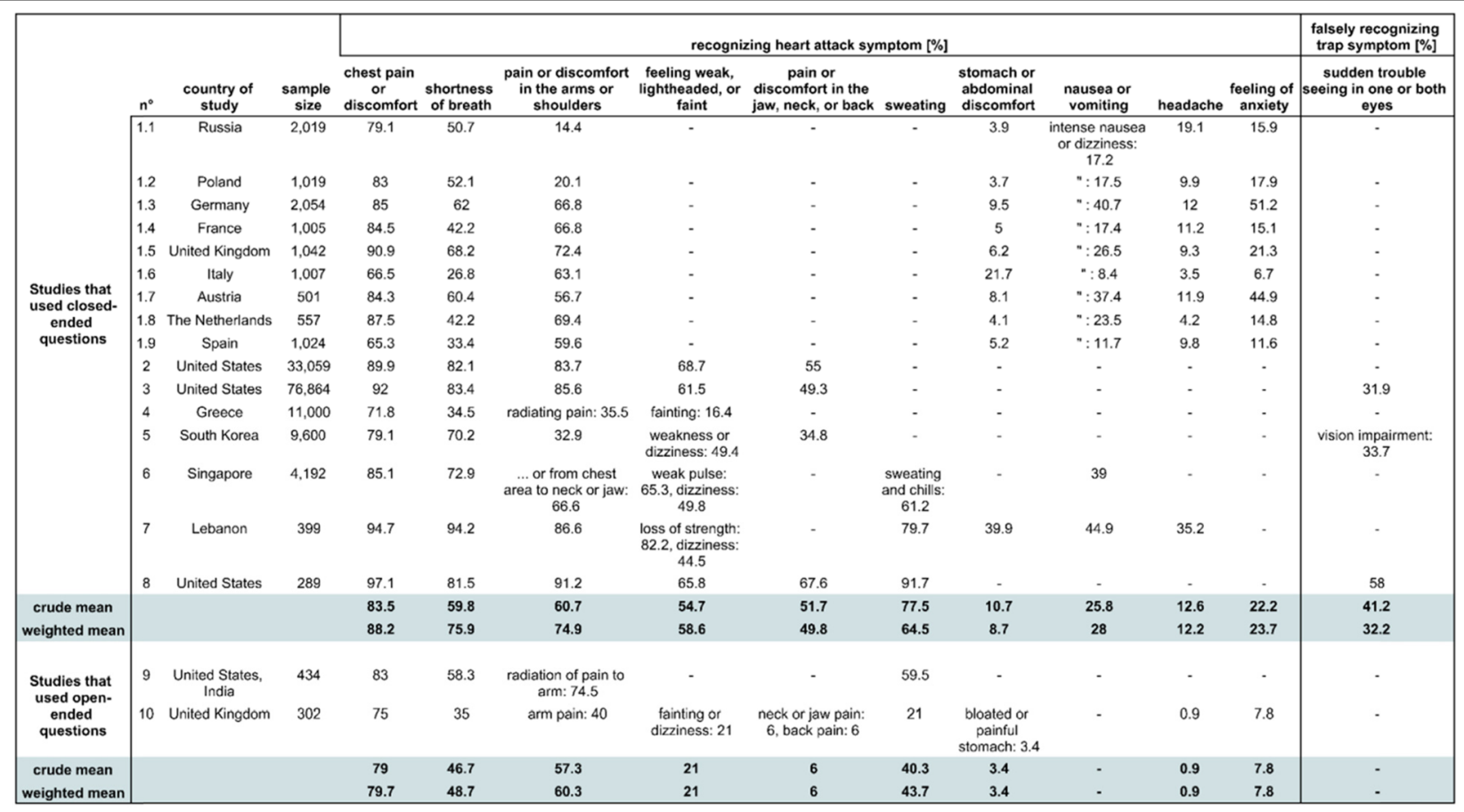

The table depicts crude mean and weighted mean for knowledge of symptoms of acute myocardial infarction in a group that was asked closed-ended questions and a group that was asked open-ended questions. If a study offered more than one knowledge percentage for a composite symptom, e.g. study 6 offered knowledge percentages on 'weak pulse' and 'dizziness' for the symptom 'feeling weak, lightheaded, or faint', we used the arithmetic mean of those percentages for our calculation. Studies included in the table: Study 1, [16] 2, [20], 3, [21] 4, [22] 5, [25] 6, [26] 7, [27] 8, [28] 9, [30] 10 [31].

\section{Cardiac group}

In the cardiac group, two studies (two samples, studies 11 and 14 in Table 4) asked the patients what symptoms they had expected, and four studies (four samples, studies 12, 13, 15, 16 in Table 4) asked the patients what symptoms they recognized as AMI symptoms. Two studies (two samples, studies 17, 18 in Table 4) used open-ended questions to assess the patients' knowledge.

Closed-ended questions With regard to closed-ended questions, the same six symptoms that were moderately known in the population group were moderately known in the cardiac group (weighted mean: 52.8-88.5\%). The mean of the weighted means of the moderately known symptoms was $70.0 \%$. Regarding the four symptoms that were insufficiently known in the population group, there were no studies for the cardiac patient group that asked about 'feeling of anxiety' and only one study that asked about 'headache', in which about $25 \%$ of participants recognized it. Similar to the population group, the symptom 'stomach or abdominal discomfort' was also insufficiently known in the cardiac group with $23.4 \%$. However, 'nausea or vomiting' was known by $36.7 \%$ in the cardiac group as opposed to $28.0 \%$ in the population group. Here, it is worth noting that an outlier in study 15 (Table 4) of $61.7 \%$ contributed to the higher result.
The trap symptom was only evaluated in two studies and the weighted mean proportion of an incorrect classification of this symptom was $33.0 \%$.

Open-ended questions In the two studies (two samples) that applied open-ended questions, similarly to the population group, the weighted mean for every symptom was smaller than when closed-ended questions were asked.

\section{Cardiac attribution}

For calculating the proportion of ACS patients who attributed their symptoms to the heart, we analyzed 25 studies (25 samples) with 14,843 patients from 16 different countries. We looked at three groups, with some participants included in all three groups. Firstly, since a number of studies only included STEMI patients, we reported the cardiac attribution of a composite STEMI group. The STEMI group included patients from 11 studies from nine different countries with 4361 participants.

Secondly, in order to allow for a more representative depiction of the group of ACS patients, we reported the attribution of the remaining studies, excluding studies that only examined STEMI patients. To that group, 15 studies from 12 different countries with 11,442 
Table 410 most frequently asked symptoms and one trap symptom in the cardiac group

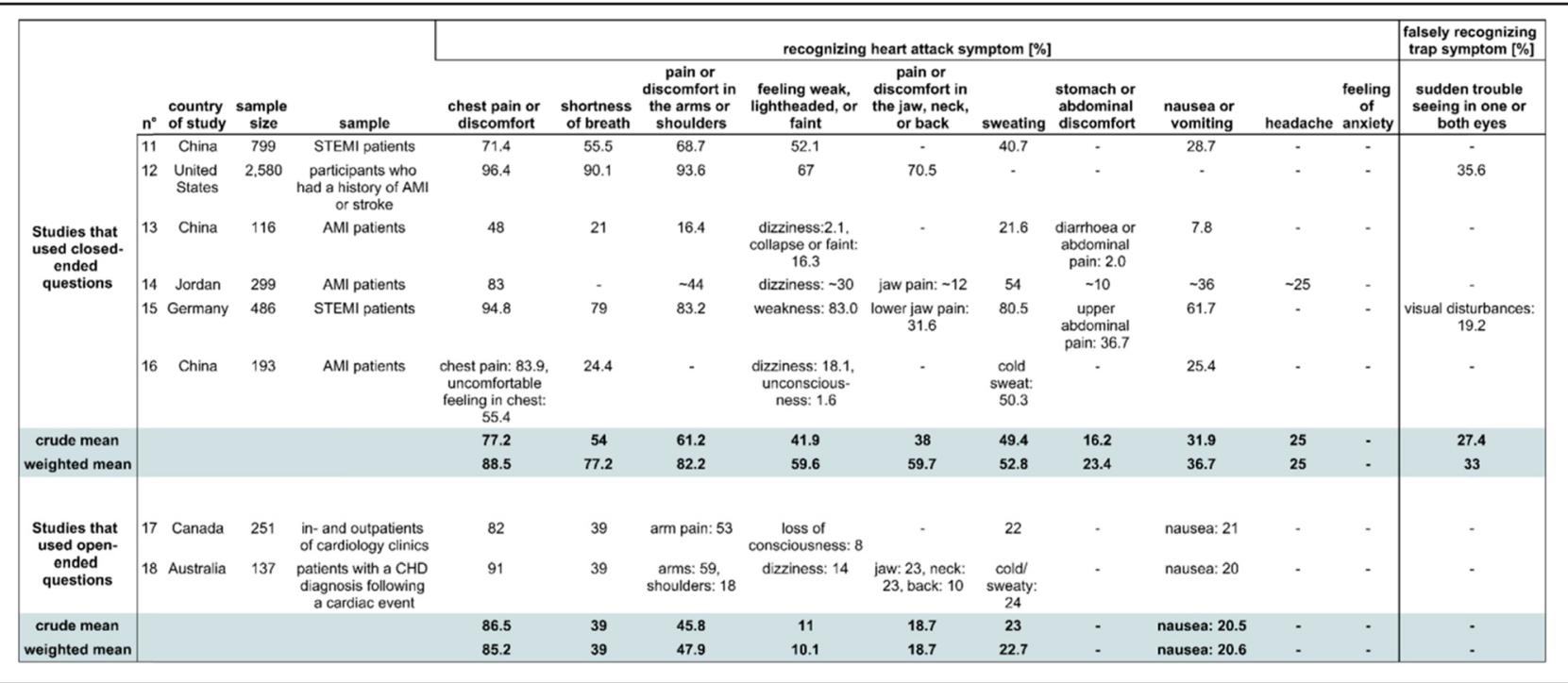

The table depicts crude mean and weighted mean for knowledge of symptoms of acute myocardial infarction in a group that was asked closed-ended questions and a group that was asked open-ended questions. For our analysis, we proceeded as described in Table 3. STEMI = ST-elevation myocardial infarction. AMI = acute myocardial infarction. CHD = coronary heart disease. Studies included in the table: Study 11, [32] 12, [33] 13, [34] 14, [40] 15, [41] 16, [42] 17, [43] 18 [44].

patients contributed data, including one study with ACS patients, one study with patients about to be investigated for ACS, one study with patients with typical oppressive chest pain indicative for AMI, and the remaining 12 studies with AMI patients, of which two studies only included first-time AMI patients.

Thirdly, we reported the cardiac attribution of all studies.

The studies mostly evaluated the cardiac attribution by asking about the patients' symptom attribution in general or specifically asking whether the patients attributed their symptoms to the heart. Some studies only looked at the symptoms-onset, by asking about the cardiac attribution of the initial symptoms. One study asked whether the reason to turn to a specialized service was that the patients believed the symptoms to be of cardiac origin [35]. The results indicate the percentage of patients who chose a cardiac interpretation.

In the STEMI group, the crude mean for cardiac attribution was $43.3 \%$ and the weighted mean $49.8 \%$. In the group of ACS patients excluding the patients from the first group, the crude mean was $39.9 \%$ and the weighted mean $43.2 \%$. All participants added up, their crude mean was $41.8 \%$ and their weighted mean $45.1 \%$.

\section{Discussion}

\section{Main findings}

In our world-wide review, we found a moderate to good knowledge of "classic" symptoms of AMI and rather insufficient knowledge of less typical symptoms. Cardiac patients had substantially higher scores in a broader knowledge assessment compared to the general population. However, 'chest pain' as a lead symptom of AMI was equally known in the general population and among cardiac patients. We also found that less than half of patients attributed their symptoms to the heart.

\section{Knowledge of atypical symptoms}

Our review showed that there is insufficient knowledge of atypical symptoms, which are especially relevant for women as they have a more atypical symptom presentation than men. While there is also considerable overlap among the symptoms men and women display, men present more often with the best known symptom 'chest pain' as well as 'sweating', which was among the best known symptoms in our comparison [103]. On the other hand, women present more often with only non-chestpain discomfort, showing symptoms as 'neck-, back- and jaw pain' which was considerably less known, or with 'nausea or vomiting' which we found to be insufficiently known [15, 103-105]. Similarly, the observation is relevant for elderly people who also experience more atypical symptoms [5, 106, 107]. This lack of knowledge of atypical symptoms might be one factor for the higher patient delay and mortality among women and the elderly [108-110].

\section{Comparison of the population and cardiac patients}

We found a higher knowledge in cardiac patients compared to the general population in a broader knowledge assessment (regarding the overall knowledge scores). When comparing the knowledge of each symptom separately, the knowledge of typical symptoms was similar among the groups, however cardiac patients had a 
higher knowledge of atypical symptoms. This suggests that the knowledge of atypical symptom might be the relevant difference.

The broader scope of knowledge in cardiac patients compared to the general population might be a consequence of their higher interest, the success of educational campaigns, or of counseling by their treating physician. It has to be considered as beneficial for delay time since previous studies observed that the time saving impact of knowledge in cardiac patients could mainly be attributed to knowledge of atypical symptoms [41]. One possible explanation for the beneficial effect is symptom congruence, [7] defined "as the extent to which one's AMI symptom experience matches those expected of an AMI" [111]. By knowing more symptoms, including atypical symptoms, patients are more likely to choose a cardiac attribution and are not confused by the experience of unknown symptoms. Symptom congruence has been found to be beneficial for cardiac attribution and a higher cardiac attribution has been shown to be significantly associated with a shorter pre-hospital delay [7, 112-114].

\section{Knowledge and its relationship to cardiac attribution}

However, in our review, despite a broad knowledge of symptoms, less than half of cardiac patients attributed their ACS (mostly AMI) to the heart when it happened.

This highlights the relevance of psychological factors. Knowledge alone is not sufficient for cardiac attribution, [9] and other components, for example various emotional factors also play a role $[12,115]$.

In fact, one study found that STEMI patients with a previous history of AMI or stent placement had a significantly lower knowledge score compared to those without it [41]. Albarqouni et al. pointed out that the driving factors might be "denial and psychological-trauma induced by the first attack" [41].

Strömbäck et al. showed that the appearance of atypical symptoms in a second AMI was not a predictor of a longer delay time [116]. One reason for this observation might be that a history of AMI seems to increase symptom congruence [111]. Therefore, the delay time in AMI survivors might not be primarily caused by a lack in knowledge but instead by psychological factors.

In the light of the above, it makes sense that despite our observed broad knowledge of symptoms in cardiac patients, a history of angina, AMI, or heart failure has not been found to have a positive impact on delay time. In fact, a history of angina or heart failure increases the delay time significantly in ACS [117].

All this highlights the significance of not merely educating patients about atypical symptoms in order to increase symptom congruence, but, maybe even more important, to prepare them psychologically. Cognitive and psychological factors that increase delay time have been observed to be denial, fear of troubling others, a lack of perceived seriousness of symptoms, a lack of perceived susceptibility to heart disease and a feeling of being able to cope with or control symptoms [118].

Therefore, we encourage future educational campaigns to not only focus their message on the knowledge of symptoms but also on overcoming psychological obstacles.

\section{Strengths, weaknesses, and sources of bias in the review}

The strength of this review is the substantial number of studies from four databases. The weakness is that there are only few studies from Africa, Russia, and South America, as well as from countries with a medium or low HDI. Our review also potentially suffers from three sources of bias. First, the results of the studies might differ by the form of knowledge assessment chosen and the composition of the samples, especially where the participants came from. Secondly, since the compared cardiac groups and population groups did not include the same set of countries, these heterogeneities might have an effect on our analysis. Thirdly, there were inconsistencies among the studies whether the knowledge of some atypical symptoms like 'headache', 'heartburn', and 'fever' contributed positively to the overall knowledge score.

\section{Conclusion}

We found a moderate to good knowledge of "classic" and rather insufficient knowledge of atypical symptoms of AMI. However, cardiac patients had a broader knowledge than the general population. As less than half of patients attributed their ACS to the heart when it happened, we see a potential to shorten delay time by educating about the symptoms, especially atypical symptoms, because they are common in the elderly and women, and because a broader knowledge increases symptom congruence. Furthermore, we encourage future campaigns to focus on overcoming psychological barriers that prevent patients from correctly identifying symptoms, attributing them to the heart, and reacting swiftly and appropriately.

\section{Supplementary information}

Supplementary information accompanies this paper at https://doi.org/10. 1186/s12872-020-01714-8.

\section{Additional file 1.}

Additional file 2.

Additional file 3.

Abbreviations

AMI: Acute myocardial infarction; ACS: Acute coronary syndrome; CAD: Coronary artery disease; STEMI: ST-elevation myocardial infarction; HDI: Human development index 


\section{Acknowledgments}

None.

\section{Declarations}

Not applicable.

\section{Authors' contributions}

$\mathrm{BB}$ and $\mathrm{RM}$ developed the research question. $\mathrm{BB}$ and $\mathrm{JH}$ conducted the review and extracted data. BB wrote the initial manuscript. JH and RM revised and commented on the manuscript. All authors read and approved the final manuscript.

\section{Funding}

None. Open Access funding enabled and organized by Projekt DEAL.

\section{Availability of data and materials}

All data generated or analyzed during this review are included in this published article and its supplementary information files.

\section{Ethics approval and consent to participate}

Not applicable.

\section{Consent for publication}

Not applicable.

\section{Competing interests}

All out authors report no conflict of interests in this work.

Received: 7 May 2020 Accepted: 24 September 2020

Published online: 14 October 2020

\section{References}

1. GBD 2015 Disease and Injury Incidence and Prevalence Collaborators. Global, regional, and national incidence, prevalence, and years lived with disability for 310 diseases and injuries, 1990-2015: a systematic analysis for the Global Burden of Disease Study 2015. Lancet. 2016;388:1545-602. https://doi.org/10.1016/S0140-6736(16)31678-6..

2. Giuseppe DL, Harry S, Paul OJ, Antman Elliott M. Time Delay to Treatment and Mortality in Primary Angioplasty for Acute Myocardial Infarction. Circulation. 2004;109:1223-5. https://doi.org/10.1161/01.CIR.0000121424. 76486.20 .

3. Guerchicoff A, Brener SJ, Maehara A, Witzenbichler B, Fahy M, Xu K, et al. Impact of delay to reperfusion on reperfusion success, infarct size, and clinical outcomes in patients with ST-segment elevation myocardial infarction: the INFUSE-AMI trial (INFUSE-anterior myocardial infarction). J Am Coll Cardiol Intv. 2014;7:733-40. https://doi.org/10.1016/j.jcin.2014.01.166.

4. Rollando D, Puggioni E, Robotti S, de Lisi A, Ferrari Bravo M, Vardanega A, et al. Symptom onset-to-balloon time and mortality in the first seven years after STEMI treated with primary percutaneous coronary intervention. Heart. 2012:98:1738-42. https://doi.org/10.1136/heartjnl-2012-302536.

5. Gillis NK, Arslanian-Engoren C, Struble LM. Acute coronary syndromes in older adults: a review of literature. J Emerg Nurs. 2014;40:270-5. https://doi. org/10.1016/j.jen.2013.03.003

6. McKinley S, Dracup K, Moser DK, Ball C, Yamasaki K, Kim CJ, Barnett M. International comparison of factors associated with delay in presentation for AMI treatment. Eur J Cardiovasc Nurs. 2004;3:225-30. https://doi.org/10. 1016/j.ejcnurse.2004.06.004

7. Fox-Wasylyshyn SM, El-Masri M, Artinian NT. Testing a model of delayed care-seeking for acute myocardial infarction. Clin Nurs Res. 2009;19:38-54. https://doi.org/10.1177/1054773809353163.

8. Moser DK, McKinley S, Dracup K, Chung ML. Gender differences in reasons patients delay in seeking treatment for acute myocardial infarction symptoms. Patient Educ Couns. 2005;56:45-54. https://doi.org/10.1016/j.pec. 2003.11.011.

9. Kirchberger I, Heier M, Wende R, von Scheidt W, Meisinger C. The patient's interpretation of myocardial infarction symptoms and its role in the decision process to seek treatment: the MONICA/KORA myocardial infarction registry. Clin Res Cardiol. 2012;101:909-16. https://doi.org/10.1007/ s00392-012-0475-8

10. Perkins-Porras L, Whitehead DL, Strike PC, Steptoe A. Pre-hospital delay in patients with acute coronary syndrome: factors associated with patient decision time and home-to-hospital delay. Eur J Cardiovasc Nurs. 2009;8:2633. https://doi.org/10.1016/j.ejcnurse.2008.05.001.

11. Coventry LL, van Schalkwyk JW, Thompson PL, Hawkins SA, Hegney DG. Myocardial infarction, patient decision delay and help-seeking behaviour: a thematic analysis. J Clin Nurs. 2017;26:1993-2005. https:/doi.org/10.1111/jocn. 13607.

12. Henriksson C, Lindahl B, Larsson M. Patients' and relatives' thoughts and actions during and after symptom presentation for an acute myocardial infarction. Eur J Cardiovasc Nurs. 2007;6:280-6. https://doi.org/10.1016/j. ejcnurse.2007.02.001

13. Meischke H, Yasui Y, Kuniyuki A, Bowen DJ, Andersen R, Urban N. How women label and respond to symptoms of acute myocardial infarction: responses to hypothetical symptom scenarios. Heart Lung. 1999;28:261-9.

14. Moher D, Liberati A, Tetzlaff J, Altman DG. Preferred reporting items for systematic reviews and meta-analyses: the PRISMA statement. BMJ. 2009; 339:b2535. https://doi.org/10.1136/bmj.b2535.

15. Mackay MH, Ratner PA, Johnson JL, Humphries KH, Buller CE. Gender differences in symptoms of myocardial ischaemia. eurheartj. 2011;32:310714. https://doi.org/10.1093/eurheartj/ehr358.

16. Mata J, Frank R, Gigerenzer G. Symptom recognition of heart attack and stroke in nine European countries: a representative survey. Health Expect. 2014;17:376-87. https://doi.org/10.1111/j.1369-7625.2011.00764.x.

17. Nicol MB, Thrift AG. Knowledge of risk factors and warning signs of stroke. Vasc Health Risk Manag. 2005;1:137-47. https://doi.org/10.2147/vhrm.1.2.137.64085.

18. Wells GA, Shea B, O'Connell D, Peterson J, Welch V, Losos M, Tugwell P. The Newcastle-Ottawa scale (NOS) for assessing the quality of nonrandomised studies in meta-analysis. 2004. http://www.ohri.ca/programs/clinical_ epidemiology/oxford.asp. Accessed 5 Aug 2020

19. Modesti PA, Reboldi G, Cappuccio FP, Agyemang C, Remuzzi G, Rapi S, et al Panethnic differences in blood pressure in Europe: a systematic review and meta-analysis. PLoS One. 2016;11:e0147601. https://doi.org/10.1371/journal. pone.0147601.

20. McGruder HE, Greenlund KJ, Malarcher AM, Antoine TL, Croft JB, Zheng Z-J. Racial and ethnic disparities associated with knowledge of symptoms of heart attack and use of 911: National Health Interview Survey, 2001. Ethn Dis. 2008;18:192-7.

21. Fang J, Gillespie C, Keenan NL, Greenlund KJ. Awareness of heart attack symptoms among US adults in 2007, and changes in awareness from 2001 to 2007. Futur Cardiol. 2011;7:311-20. https://doi.org/10.2217/fca.10.111.

22. George I, Tsolakoglou J, Stergiannis P, Chalari E, Christodoulou E, Fildissis G. Do Greek citizens have minimum knowledge about heart attack? A Survey. Health Sci J. 2015;9:1-6.

23. Kopec G, Sobien B, Podolec M, Dziedzic H, Zarzecka J, Loster B, et al. Knowledge of a patient-dependant phase of acute myocardial infarction in polish adults: the role of physician's advice. Eur J Pub Health. 2011;21:603-8. https://doi.org/10.1093/eurpub/ckq110.

24. Dracup K, Moser DK, McKinley S, Ball C, Yamasaki K, Kim C-J, et al. An international perspective on the time to treatment for acute myocardial infarction. J Nurs Scholarsh. 2003;35:317-23. https://doi.org/10.1111/j.15475069.2003.00317.x

25. Kim H-S, Lee H, Kim K, Park H-K, Park K-S, Kang GW, et al. The general Public's awareness of early symptoms of and emergency responses to acute myocardial infarction and related factors in South Korea: a National Public Telephone Survey. J Epidemiol. 2016;26:233-41. https://doi.org/10.2188/jea.JE20150074.

26. Quah JLJ, Yap S, Cheah SO, Ng YY, Goh ES, Doctor N, et al. Knowledge of signs and symptoms of heart attack and stroke among Singapore residents. Biomed Res Int. 2014;2014:572425. https://doi.org/10.1155/ 2014/572425.

27. Noureddine S, Froelicher ES, Sibai AM, Dakik H. Response to a cardiac event in relation to cardiac knowledge and risk perception in a Lebanese sample: a cross sectional survey. Int J Nurs Stud. 2010;47:332-41. https://doi.org/10. 1016/j.jijnurstu.2009.07.002

28. Banharak S, Zahrli T, Matsuo H. Public knowledge about risk factors, symptoms, and first decision-making in response to symptoms of heart attack among lay people. Pacific Rim Int J Nurs Res. 2018;22:18-29.

29. Hwang SY, Ryan CJ, Zerwic JJ. Korean immigrants' knowledge of heart attack symptoms and risk factors. J Immigr Minor Health. 2008;10:67-72. https://doi.org/10.1007/s10903-007-9053-y.

30. Gupta V, Dhawan N, Saeed O, Bhoi S. Knowledge of myocardial infarction in sample populations: a comparison of a developed and a developing nation: 3.5-008. Trop Med Int Health. 2011;16. 
31. Whitaker S, Baldwin T, Tahir M, Choudhry O, Senior A, Greenfield S. Public knowledge of the symptoms of myocardial infarction: a street survey in Birmingham, England. Fam Pract. 2012;29:168-73. https://doi.org/10.1093/ fampra/cmr079.

32. Song L, Yan H-B, Yang J-G, Sun Y-H, Hu D-Y. Impact of patients' symptom interpretation on care-seeking behaviors of patients with acute myocardial infarction. Chin Med J. 2010;123:1840-5.

33. Pearlman D, Affleck P, Goldman D. Disparities in awareness of the warning signs and symptoms of a heart attack and stroke among Rhode Island adults. Med Health Rhode Island. 2011;94:183-5.

34. Gao Y, Zhang H-J. The effect of symptoms on prehospital delay time in patients with acute myocardial infarction. J Int Med Res. 2013;41:1724-31. https://doi.org/10.1177/0300060513488511.

35. Franco B, Rabelo ER, Goldemeyer S, Souza EN. Patients with acute myocardial infarction and interfering factors when seeking emergency care: implications for health education. Revista Latino-Americana de Enfermagem. 2008;16:414-8

36. Lutfiyya MN, Cumba MT, McCullough JE, Barlow EL, Lipsky MS. Disparities in adult African American women's knowledge of heart attack and stroke symptomatology: an analysis of 2003-2005 behavioral risk factor surveillance survey data. J Women's Health (Larchmt). 2008;17:805-13. https://doi.org/10. 1089/jwh.2007.0599.

37. Lutfiyya MN, Lipsky MS, Bales RW, Cha I, McGrath C. Disparities in knowledge of heart attack and stroke symptoms among adult men: an analysis of behavioral risk factor surveillance survey data. J Natl Med Assoc. 2008;100:1116-24. https://doi.org/10.1016/S0027-9684(15)31483-8.

38. Fussman C, Rafferty AP, Reeves MJ, Zackery S, Lyon-Callo S, Anderson B. Racial disparities in knowledge of stroke and heart attack risk factors and warning signs among Michigan adults. Ethn Dis. 2009;19:128-34.

39. Memiş S, Evci ED, Ergin F, Beşer E. A population- based study on awareness of heart attack in Aydin city-Turkey. Anadolu Kardiyol Derg. 2009;9:304-10.

40. Abed MA, Ali RMA, Abu Ras MM, Hamdallah FO, Khalil AA, Moser DK. Symptoms of acute myocardial infarction: a correlational study of the discrepancy between patients' expectations and experiences. Int J Nurs Stud. 2015;52:1591-9. https://doi.org/10.1016/j.jjnurstu.2015.06.003.

41. Albarqouni L, Smenes K, Meinertz T, Schunkert H, Fang X, Ronel J, Ladwig KH. Patients' knowledge about symptoms and adequate behaviour during acute myocardial infarction and its impact on delay time: findings from the multicentre MEDEA study. Patient Educ Couns. 2016;99:1845-51. https://doi. org/10.1016/j.pec.2016.06.007

42. Yan J, You L-M, He J-G, Wang J-F, Chen L, Liu B-L, et al. IIIness perception among Chinese patients with acute myocardial infarction. Patient Educ Couns. 2011;85:398-405. https://doi.org/10.1016/j.pec.2010.11.010.

43. Gill R, Chow C-M. Knowledge of heart disease and stroke among cardiology inpatients and outpatients in a Canadian inner-city urban hospital. Can J Cardiol. 2010;26:537-41.

44. Gallagher R, Roach K, Belshaw J, Kirkness A, Sadler L, Warrington D. A pretest post-test study of a brief educational intervention demonstrates improved knowledge of potential acute myocardial infarction symptoms and appropriate responses in cardiac rehabilitation patients. Aust Crit Care 2013;26:49-54. https://doi.org/10.1016/j.aucc.2012.01.002.

45. Dracup K, McKinley S, Doering LV, Riegel B, Meischke H, Moser DK, et al. Acute coronary syndrome: what do patients know? Arch Intern Med. 2008; 168:1049-54. https://doi.org/10.1001/archinte.168.10.1049.

46. Chan CW, Lopez V, Chung JWY. A survey of coronary heart disease knowledge in a sample of Hong Kong Chinese. Asia Pac J Public Health. 2011;23:288-97. https://doi.org/10.1177/1010539509345869.

47. Kim EM, Hwang SY, Kim AL. Knowledge of stroke and heart attack symptoms and risk factors among rural elderly people: a questionnaire survey. Korean Circ J. 2011;41:259-64. https://doi.org/10.4070/kcj.2011.41.5.259.

48. Henriksson C, Larsson M, Arnetz J, Berglin-Jarlöv M, Herlitz J, Karlsson J-E, et al. Knowledge and attitudes toward seeking medical care for AMIsymptoms. Int J Cardiol. 2011;147:224-7. https://doi.org/10.1016/j.ijcard.2009. 08.019.

49. Kirchberger I, Meisinger C, Heier M, Kling B, Wende R, Greschik C, et al Patient-reported symptoms in acute myocardial infarction: differences related to ST-segment elevation. J Intern Med. 2011;270:58-64. https://doi. org/10.1111/j.1365-2796.2011.02365.x.

50. Poomsrikaew O, Ryan CJ, Zerwic JJ. Knowledge of heart attack symptoms and risk factors among native Thais: a street-intercept survey method. Int J Nurs Pract. 2010;16:492-8. https://doi.org/10.1111/j.1440-172X.2010.01874.X.
51. Kim H-S, Lee K-S, Eun SJ, Choi S-W, Kim DH, Park T-H, et al. Gender differences in factors related to Prehospital delay in patients with STsegment elevation myocardial infarction. Yonsei Med J. 2017;58:710-9. https://doi.org/10.3349/ymj.2017.58.4.710.

52. Lutfiyya MN, Bardales R, Bales R, Aguero C, Brady S, Tobar A, et al. Awareness of heart attack and stroke symptoms among Hispanic male adults living in the United States. J Immigr Minor Health. 2010;12:761-8. https://doi.org/10.1007/s10903-009-9250-y.

53. Venkatesan VCK, Madhavi S, RSK, PK. A study to explore the factors related to treatment seeking delay among adults diagnosed with acute myocardial infarction at KMCH, Coimbatore. Indian Heart Journal. 2018;70:793-801. https://doi.org/10.1016/j.ihj.2018.01.007.

54. Vavouranakis I, Fanioudaki A, Lamprogiannakis E, Baltzakis I, Sidiropoulou K, Porfiri E, Ganotakis ES. Delays incurred during acute myocardial infarction: a comparative study of rural and urban populations in Greece. Rural Remote Health. 2010;10:1271.

55. Swanoski MT, Lutfiyya MN, Amaro ML, Akers MF, Huot KL. Knowledge of heart attack and stroke symptomology: a cross-sectional comparison of rural and non-rural US adults. BMC Public Health. 2012;12:283. https://doi.org/10. 1186/1471-2458-12-283.

56. Flink LE, Sciacca RR, Bier ML, Rodriguez J, Giardina E-GV. Women at risk for cardiovascular disease lack knowledge of heart attack symptoms. Clin Cardiol. 2013;36:133-8. https://doi.org/10.1002/clc.22092.

57. Lambert C, Vinson S, Shofer F, Brice J. The relationship between knowledge and risk for heart attack and stroke. J Stroke Cerebrovasc Dis. 2013:22:9961001. https://doi.org/10.1016/j.jstrokecerebrovasdis.2012.02.002.

58. Abed MA, Khalil AA, Moser DK. The contribution of symptom incongruence to Prehospital delay for acute myocardial infarction symptoms among Jordanian patients. Res Nurs Health. 2015;38:213-21. https://doi.org/10.1002/ nur.21658.

59. Patnaik L, Pattanaik S, Sahu T, Bijan KP. Awareness of symptoms and risk factors of Myocardial Infarction among adults seeking health care from a rural hospital of India. J Cardiovasc Dis Res. 2016;7:83. https://doi.org/10. 5530/jcdr.2016.2.5

60. Fukuoka Y, Lisha NE, Vittinghoff E. Comparing Asian American Women's Knowledge, Self-Efficacy, and Perceived Risk of Heart Attack to Other Racial and Ethnic Groups: The mPED Trial. J Womens Health (Larchmt). 2017;26: 1012-9. https://doi.org/10.1089/jwh.2016.6156.

61. George L, Ramamoorthy L, Satheesh S, Saya RP, Subrahmanyam DKS. Prehospital delay and time to reperfusion therapy in ST elevation myocardial infarction. J Emerg Trauma Shock. 2017;10:64-9. https://doi.org/ 10.4103/0974-2700.201580.

62. Koc S, Durna Z, Akin S. Interpretation of symptoms as a cause of delays in patients with acute myocardial infarction, Istanbul, Turkey. East Mediterr Health J. 2017:23:287-94. https://doi.org/10.26719/2017.23.4.287.

63. Lavery T, Greenslade JH, Parsonage WA, Hawkins T, Dalton E, Hammett C, Cullen L. Factors influencing choice of pre-hospital transportation of patients with potential acute coronary syndrome: an observational study. Emerg Med Aust. 2017;29:210-6. https://doi.org/10.1111/1742-6723.12735.

64. Verulava T, Maglakelidze T, Jorbenadze R. Hospitalization timeliness of patients with myocardial infarction. East J Med. 2017;22:103-9.

65. Li PWC, Yu DSF. Predictors of pre-hospital delay in Hong Kong Chinese patients with acute myocardial infarction. Eur J Cardiovasc Nurs. 2017;17:7584. https://doi.org/10.1177/1474515117718914.

66. Yan H-B, Song L, Chen H, Zhang J, Li S-Y, Li Q-X, et al. Factors influencing ambulance use in patients with ST-elevation myocardial infarction in Beijing, China. Chin Med J. 2009;122:272-8. https://doi.org/10.3760/cma.j.issn.03666999.2009 .03 .007$.

67. Song L, Yan H-B, Hu D-Y, Yang J-G, Sun Y-H. Pre-hospital care-seeking in patients with acute myocardial infarction and subsequent quality of care in Beijing. Chin Med J. 2010;123:664-9. https://doi.org/10.3760/cma.j.issn.03666999.2010.06.005.

68. Motalebi SA. Patients delay in seeking medical care for acute myocardial infarction symptoms. Rawal Med J. 2013;38(2):109-112.

69. Alshahrani H, McConkey R, Wilson J, Youssef M, Fitzsimons D. Female gender doubles pre-hospital delay times for patients experiencing ST segment elevation myocardial infarction in Saudi Arabia. Eur J Cardiovasc Nurs. 2013;13:399-407. https://doi.org/10.1177/1474515113507159.

70. Mussi FC, Mendes AS, de Queiroz TL, Costa ALS, Pereira Á, Caramelli B. Prehospital delay in acute myocardial infarction: judgement of symptoms and resistance to pain. Revista da Associação Médica Brasileira. 2014;60:63-9. 
71. Ribeiro V, Melão F, Duarte Rodrigues J, Machado Leite S, Garcia RM, Dias P, Maciel MJ. Perception of illness symptoms in patients with acute coronary syndrome: a need to improve. Rev Port Cardiol. 2014;33:519-23. https://doi. org/10.1016/j.repc.2013.09.017.

72. Bell M, Lommel T, Fischer JG, Lee JS, Reddy S, Johnson MA. Improved recognition of heart attack and stroke symptoms after a communitybased intervention for older adults, Georgia, 2006-2007. Prev Chronic Dis. 2009;6:A41.

73. Crumlish CM, Magel CT. Patient education on heart attack response: is rehearsal the critical factor in knowledge retention? Medsurg Nurs. 2011;20: 310-7.

74. Athbi $\mathrm{H}$, Hassan $\mathrm{H}$. Knowledge of patients with coronary heart disease about secondary prevention measures. Indian J Public Health Res Dev. 2019; 10:945. https://doi.org/10.5958/0976-5506.2019.00418.2.

75. Poulter C, Stewart M, Fitzpatrick C, Keech W, Stavreski B, Grenfell R. 'BeAWARE': supporting non-clinical staff within general practice to promptly identify patients presenting with warning signs of heart attack or stroke. Aust Fam Physician. 2014;43:394-8.

76. Yan J, You L-M, Liu B-L, Jin S-Y, Zhou J-J, Lin C-X, et al. The effect of a telephone follow-up intervention on illness perception and lifestyle afte myocardial infarction in China: A randomized controlled trial. Int J Nurs Stud. 2014;51:844-55. https://doi.org/10.1016/j.jinurstu.2013.10.011.

77. Kaur S, Nallappanahally M. A Study to Assess the Effectiveness of Awareness Programme in Term of Knowledge Regarding Early Symptoms of Myocardial Infarction among Bank Employees of Selected Banks at Moradabad, U.P. Indian J Public Health Res Dev. 2017;8:120. https://doi.org/ 10.5958/0976-5506.2017.00024.9.

78. Tummala SR, Farshid A. Patients' understanding of their heart attack and the impact of exposure to a media campaign on pre-hospital time. Heart Lung Circ. 2015;24:4-10. https://doi.org/10.1016/j.hlc.2014.07.063.

79. Bayrak D, Tosun N. Determination of nursing activities for prevention of heart attack and stroke in hypertension patients; 2018.

80. McKinley S, Dracup K, Moser DK, Riegel B, Doering LV, Meischke H, et al. The effect of a short one-on-one nursing intervention on knowledge, attitudes and beliefs related to response to acute coronary syndrome in people with coronary heart disease: a randomized controlled trial. Int J Nurs Stud. 2009; 46:1037-46. https://doi.org/10.1016/j.ijnurstu.2009.01.012.

81. Kalman M, Stewart PS, Wells M, Blumkin A, Pribulick M, Rolland R. Education to increase women's knowledge of female myocardial infarction symptoms. J N Y State Nurs Assoc. 2013:43:11-6.

82. Fang J, Luncheon C, Ayala C, Odom E, Loustalot F. Awareness of Heart Attack Symptoms and Response Among Adults - United States, 2008 , 2014, and 2017. MMWR Morb. Mortal. Wkly. Rep. 2019;68:101-6. https://doi. org/10.15585/mmwr.mm6805a2.

83. Guan W, Venkatesh AK, Bai X, Xuan S, Li J, Li X, et al. Time to hospital arrival among patients with acute myocardial infarction in China: a report from China PEACE prospective study. Eur Heart J Qual Care Clin Outcomes. 2018; 5:63-71. https://doi.org/10.1093/ehjqcco/qcy022.

84. Mikulik R, Vondráčková L, Pokorná H, Svobodová V, Grecu AM, Vítovec J, et al. Feasibility and efficacy of an educational programme to increase awareness of stroke and heart attack in children. Health Educ J. 2019;78: 812-23. https://doi.org/10.1177/0017896919849080.

85. Rezaei H, Jamil D, Ebadi A, Ghanei GR. Psychometric properties of the Persian version of the instrument for assessing cardiac patients' knowledge, attitude, and beliefs regarding heart attack. Int Cardiovasc Res J. 2019;13:68-74.

86. Sederholm Lawesson S, Isaksson R-M, Ericsson M, Ängerud K, Thylén I. Gender disparities in first medical contact and delay in ST-elevation myocardial infarction: a prospective multicentre Swedish survey study. BMJ Open. 2018;8:e020211. https://doi.org/10.1136/bmjopen-2017-020211.

87. Bray Janet E, Lahn S, Harry P, Bill S, Judith F. Abstract 20858: Australian's Awareness of Heart Attack Symptoms and Action Improves With a Mass Media Warning Signs Campaign. Circulation. 2016;134:A20858. https://doi. org/10.1161/circ.134.suppl_1.20858.

88. Castillo EM, Chan TC, Killeen JP, Vilke GM. 228 knowledge of acute myocardial infarction symptoms: do sex differences still exist? Ann Emerg Med. 2012;60:S83. https://doi.org/10.1016/j.annemergmed.2012. 06.206 .

89. Lichtman Judith H, Haikun B, Leifheit-Limson Erica C, Lorenze Nancy P, Mitra D, Basmah S, et al. Abstract 17831: Sex Differences in Symptoms Presentation and Perception of Symptoms among Young Patients with MI:
The VIRGO Study. Circulation. 2012;126:A17831. https://doi.org/10.1161/circ. 126.suppl 21.A17831.

90. Løvlien M. Symptoms of acute myocardial infarction - what influence the Patients' interpretation of symptoms as cardiac in origin?: PN-008. Cardiology. 2013;125:36.

91. Alshahrani H, Fitzsimons D, McConkey R, Wilson J, Youssef M. The impact of patient's gender and cultural factors in prehospital delay in patients presenting with myocardial infarction in KSA. J Saudi Heart Assoc. 2013;25: 132-3. https://doi.org/10.1016/j.jsha.2013.03.078.

92. Connolly K, Dmetrichuk K, Qureshi R, Natarajan M, Schwalm J-D. 264 barriers to EMS utilization during STEMI. Can J Cardiol. 2012;28:S190. https://doi.org/ 10.1016/j.cjca.2012.07.248.

93. Norekvål T, Chan Y-K, Carrington M, Stewart S, Thompson D. PW194 perceived causes and symptom recognition of acute myocardial infarction: systematic misconceptions among 536 survivors and 511 carers. Glob Heart. 2014;9:e296-7. https://doi.org/10.1016/j.gheart.2014.03.2296.

94. Ramirez-Moreno JM, Alonso-Gonzalez R, Millan-Nunez MV, Pons MA, Querol $R$, Munoz-Santos L, et al. Abstract P584: Predictors for adequate knowledge of symptom clusters of heart attack in the general population of Extremadura, Spain. Eur Heart J. 2011;Issue suppl_1(P584):69.

95. Langner-Leiter E, Greenberg K, Wetzler S, Donchin M, Littman I, Nubani M, et al. Cardiovascular disease knowledge, physician communication and health information sources in ultra-orthodox hasidic jewish women: 250. Eur J Prev Cardiol. 2016;23.

96. Granieri Michael J, Koulova Anna, Cordova Juan Pablo, Agarwal Vikram, Trignano Sarah, Tamis-Holland Jacqueline E. Abstract 271: Knowledge of Heart Disease in Female and Male College Students. Circulation. 2015;8: A271-A271. doi:https://doi.org/10.1161/circoutcomes.8.suppl_2.271.

97. Danny SS, Juzar DA, Firdaus I, Zamroni D, Widyantoro B, Rmalita I, Tobing D. Gender differences on cardiovascular risk perception and heatlh-care seeking behaviour among patients surviving myocardial infarction. Eur Heart J. 2011;:Issue suppl_1(P584):B46.

98. Bray Janet E, Dion S, Phil N, Susie C, James S, Judith F. Abstract 16114: How Does the Symptom Experience Differ From Patient's Expectations of What Having a Heart Attack is Like? Circulation. 2014;130:A16114. https://doi.org/ 10.1161/circ.130.suppl_2.16114.

99. Wilson E, Cordova JP, Bavishi CP, Tamis-Holland J. Women fail to recognize symptoms of myocardial infaction leading to delays in hospital presentation. Cardiology. 2017;137(suppl 1):236.

100. Kolo PM, Ogunmodede JA, Deleojo BF, Katibi IA. O024 public knowledge of heart attack symptoms and prevalence of self reported cardiovascular risk factors in Ilorin, Nigeria. Global Heart. 2014;1:e7.

101. Nashi N, Tham SM, Mak MHW, Goh JH, Kong CH, Lee KS, et al. Abstract OPQHSR-07: Investigating the Awareness of the Symptoms, Risk Factors and Management of Acute Myocardial Infarction in the General Singaporean Population. Ann Acad Med. 2013;42:224.

102. UNDP. 2018 Statistical Update: Human Development Indices and Indicators. New York. 2018. http://hdr.undp.org/en/content/human-developmentindices-indicators-2018-statistical-update. Accessed 5 Aug 2020.

103. van Oosterhout Roos EM, de Boer Annemarijn R, Maas Angela HEM, Rutten Frans H, Bots Michiel L, Peters Sanne AE. Sex Differences in Symptom Presentation in Acute Coronary Syndromes: A Systematic Review and Metaanalysis. J Am Heart Assoc. 2020;9:e014733. https://doi.org/10.1161/JAHA. 119.014733

104. Goldberg RJ, O’Donnell C, Yarzebski J, Bigelow C, Savageau J, Gore JM. Sex differences in symptom presentation associated with acute myocardial infarction: a population-based perspective. Am Heart J. 1998;136:189-95. https://doi.org/10.1053/hj.1998.v136.88874.

105. Meischke H, Larsen MP, Eisenberg MS. Gender differences in reported symptoms for acute myocardial infarction: impact on prehospital delay time interval. Am J Emerg Med. 1998;16:363-6. https://doi.org/10.1016/S07356757(98)90128-0.

106. Grosmaitre $P$, Le Vavasseur $O$, Yachouh E, Courtial Y, Jacob X, Meyran S, Lantelme $P$. Significance of atypical symptoms for the diagnosis and management of myocardial infarction in elderly patients admitted to emergency departments. Arch Cardiovasc Dis. 2013;106:586-92. https://doi. org/10.1016/j.acvd.2013.04.010.

107. Woon VC, Lim KH. Acute myocardial infarction in the elderly--the differences compared with the young. Singap Med J. 2003;44:414-8.

108. Nguyen HL, Saczynski JS, Gore JM, Goldberg RJ. Age and sex differences in duration of prehospital delay in patients with acute myocardial infarction: a 
systematic review. Circ Cardiovasc Qual Outcomes. 2010;3:82-92. https://doi. org/10.1161/CIRCOUTCOMES.109.884361.

109. Liakos M, Parikh PB. Gender disparities in presentation, management, and outcomes of acute myocardial infarction. Curr Cardiol Rep. 2018;20:64. https://doi.org/10.1007/s11886-018-1006-7.

110. Wechkunanukul K, Grantham H, Clark RA. Global review of delay time in seeking medical care for chest pain: an integrative literature review. Australian Critical Care. 2017;30:13-20. https://doi.org/10.1016/j.aucc.2016.04. 002.

111. Fox-Wasylyshyn S. Predictors of symptom congruence among patients with acute myocardial infarction. J Cardiovasc Nurs. 2012;27:325-33. https://doi. org/10.1097/JCN.0b013e31822275c7.

112. Horne R, James D, Petrie K, Weinman J, Vincent R. Patients' interpretation of symptoms as a cause of delay in reaching hospital during acute myocardial infarction. Heart. 2000;83:388-93. https://doi.org/10.1136/heart.83.4.388.

113. King KB, McGuire MA. Symptom presentation and time to seek care in women and men with acute myocardial infarction. Heart \& Lung. 2007;36: 235-43. https://doi.org/10.1016/j.hrtlng.2006.08.008.

114. Gärtner C, Walz L, Bauernschmitt E, Ladwig K-H. The causes of prehospital delay in myocardial infarction. Dtsch Arztebl Int. 2008;105:286-91. https:// doi.org/10.3238/arztebl.2008.0286.

115. Alonzo AA, Reynolds NR. The structure of emotions during acute myocardial infarction: a model of coping. Soc Sci Med. 1998:46:1099-110. https://doi.org/10.1016/s0277-9536(97)10040-5.

116. Strömbäck U, Engström Å, Lundqvist R, Lundblad D, Vikman I. The second myocardial infarction: is there any difference in symptoms and prehospital delay compared to the first myocardial infarction? Eur I Cardiovasc Nurs. 2018;17:652-9. https://doi.org/10.1177/1474515118777391.

117. Moser Debra K, Kimble Laura P, Alberts Mark J, Angelo A, Croft Janet B, Kathleen $\mathrm{D}$, et al. Reducing delay in seeking treatment by patients with acute coronary syndrome and stroke. Circulation. 2006;1 14:168-82. https:/ doi.org/10.1161/CIRCULATIONAHA. 106.176040.

118. Xie L, Huang S-F, Hu Y-Z. Factors influencing pre-hospital patient delay in patients with acute myocardial infarction. Chin Nurs Res. 2015;2:75-9. https://doi.org/10.1016/j.cnre.2015.04.002.

\section{Publisher's Note}

Springer Nature remains neutral with regard to jurisdictional claims in published maps and institutional affiliations.

Ready to submit your research? Choose BMC and benefit from:

- fast, convenient online submission

- thorough peer review by experienced researchers in your field

- rapid publication on acceptance

- support for research data, including large and complex data types

- gold Open Access which fosters wider collaboration and increased citations

- maximum visibility for your research: over $100 \mathrm{M}$ website views per year

At $\mathrm{BMC}$, research is always in progress.

Learn more biomedcentral.com/submissions 